https://helda.helsinki.fi

How to make a lecture course an engaging learning experience?

\author{
Lonka, Kirsti
}

2012-05-11

Lonka , K \& Ketonen, E 2012 , ' How to make a lecture course an engaging learning

experience? ' , Studies for the learning society , vol. 2 , no. 2-3 , pp. 63-74 . https://doi.org/10.2478/v10240-012-0006

http://hdl.handle.net/10138/232980

https://doi.org/10.2478/v10240-012-0006-1

cc_by_nc_nd

publishedVersion

Downloaded from Helda, University of Helsinki institutional repository.

This is an electronic reprint of the original article.

This reprint may differ from the original in pagination and typographic detail.

Please cite the original version. 


\title{
HOW TO MAKE A LECTURE COURSE AN ENGAGING LEARNING EXPERIENCE?
}

\author{
KIRSTI LONKA, ELINA KETONEN \\ University of Helsinki, Finland
}

\begin{abstract}
This paper investigates engagement and active learning in university mass education. It presents the results of an empirical study on the level of interest and the academic emotions that were experienced during an engaging lecture course, and how such variables were related to flow experience, self-study time, and study success.
\end{abstract}

The participants $(n=107)$ were Finnish first-year teacher students in an educational psychology lecture course. The data were collected by using a questionnaire that measured interest, academic emotions, sense of competence, challenge experienced, and self-study time five days before the final examination. Correlations among variables were measured, a step-wise cluster analysis and two ANOVA tests conducted.

The participants were highly engaged and interested during the course. Interest, enthusiasm, sense of competence, and self-study time correlated positively with the grade awarded for the course. Three clusters (emotional profiles) were identified: engaged (36\%), unstressed (25\%), and anxious (39\%) student groups. Engaged students spent the most hours in self-study and received the best grades. Unstressed students were the least active in self-study and also achieved the lowest grades.
Interest and sense of competence were decisive variables in successful studying during an engaging lecture course. Opportunities to develop blended learning environments that foster active learning in lectures were further discussed.

Keywords: academic achievement, academic emotions, engagement, engaging learning, flow, interest, higher education, lecture, teacher education

\section{INTRODUCTION}

It was stated decades ago that university education should target the active construction of knowledge and that lectures may not be the optimal route to achieving this goal (Gibbs \& Jenkins, 1992; McKeachie, 2006). "Active learning is an approach to teaching in which the teacher recognises that it is the learner who does the learning and therefore makes every effort to facilitate this process" (Cantillon, $2010,20)$. Especially in mass education, practices and conventions in higher education are still very much based on the idea that the task of the teacher is to transmit knowledge. Ideas of learning and epistemological beliefs are very slow to change and teachers often entertain quite conventional ideas of learning (Lonka, Joram, \& Bryson, 1996; Trigwell \& Prosser, 1996). Both intellectual and emotional challenges in higher education, however, are huge at the moment.

Professor Dr. KIRSTI LONKA holds the Chair of Educational Psychology at University of Helsinki, Finland. She has published extensively on university student learning, innovative teaching and learning methods in higher education, study strategies, and medical education. She is Vice Dean of the Faculty of Behavioural Sciences, University of Helsinki, Finland.

ELINA KETONEN is a PhD student in Educational Psychology at the Department of Teacher Educaion, Faculty of Behavioural Sciences, University of Helsinki, Finland. Her research interests are academic emotions, motivation and learning in the context of higher education. 
What can we do to help our students to learn how to deal with them? The focus of this paper is to explore new ways of approaching practices of higher education, especially in the question of how to make mass instruction more engaging.

Future citizens need to solve increasingly complex, ill-defined problems (Lonka, 1997). We need to constantly reconsider and reconceptualise our educational practices. Learning environments and learning tools, the nature of knowledge, and the goals of education are constantly changing (Bereiter, 2002). Technology, in particular, co-evolves rapidly with novel learning practices. Learning becomes increasingly blended, which means that face-to-face instruction is often combined with computer-mediated learning environments (Bonk \& Graham, 2006). It may no longer be advisable to talk about "learning environments" or "technological tools", but rather, about knowledge building environments (KBE) that enhance collaborative efforts to create and continually improve ideas (Scardamalia \& Bereiter, 2003).

Emotions and motivation have an increasing role in explaining university students learning and studying (Lonka et al., 2008). The relationships between emotions, motivation, study success and well-being have been less frequently studied (for an example see Heikkilä et al., in press). Positive psychology is a new movement in the field of psychology. The importance of positive experience has become one of the cornerstones of understanding the components of student well-being (Salmela-Aro \& Schoon, 2010). Students attending mass lectures were reported to feel bewildered, overwhelmed and anonymous (Ward \& Jenkins, 1992). Modern research indicates that such experiences are a threat to students' well-being (Dahlin, Joneboerg, \& Runeson, 2005). It is important to design ways of teaching and learning that promote engagement and active learning.

\section{What are academic emotions?}

The term academic emotion is often defined as emotion experienced in academic settings and related to studying, learning or instruction (Pekrun et al., 2002). Such emotions are, for example, enjoyment of learning, pride of success, or test-related anxiety. Until recently, academic emotions have largely been neglected by educational psychology, with the exception of test anxiety.

Pekrun (2005) suggests that students' emotions are manifold and much richer in nature than traditional views seem to suggest. All kinds of human emotions may play a role in learning and studying, including self- and task-related emotions, social emotions, and the variants of discrete emotions. Ainley, Corrigan and Richardson (2005) indicated in their study that situational emotions can transform into interest among other things. Their findings imply that emotions may be central to the arousal and maintenance of students' interest, motivation, volition, and effort. It has also been shown that academic emotions are significantly related to students' learning strategies, cognitive processes, self-regulation, and academic achievement, as well as to classroom antecedents, personality and psychological health (Pekrun et al., 2002).

Furthermore, new contextual ways of measuring academic emotions have been developed. For instance, our Finnish research group measured academic emotions, interest, sense of competence and challenge using the Contextually Activated Sampling System (CASS) method (Litmanen et al., in press; Muukkonen et al., 2007; 2008; Tolvanen et al., 2011).

Academic emotions are social in nature and emotional experiences are always situated in the immediate and broader social context (Opt't Eynde \& Turner, 2006). It has also been shown that teachers can influence their students' emotions, although it may be difficult to make teachers change their instructional behaviour such that student emotions are fostered (Pekrun, 2005). However, research on the impact of classroom instruction, learning environments, and social contexts on the development of academic emotions is scarce (Pekrun, 2005).

While it seems clear that students' emotions develop in social contexts, we do not yet know how this process can be fostered such that enjoyment of learning is enhanced, and that negative emotions hindering learning are prevented or put to productive use. Future research on academic emotions should include more intervention studies and provide information on how instruction and social interaction with students can be modified in such a way that students' emotional development is fostered.

In the present study we investigate what kind of academic emotions students experience in the context of a student-activating lecture course and how those emotions are related to their academic success on the same course. The academic emotions are measured contextually by using a questionnaire during a lecture situation.

\section{The role of interest in learning}

Interest may be defined as a psychological state that is characterised by an affective component of positive emotion and a cognitive component of concentration (Hidi \& Renninger, 2006). Interest develops in the interaction between a person and the surrounding context. Such instruction that activates prior knowledge, supports autonomy and a sense of control, and where 
the goals are transparent, was reported as promoting interest (Tsai et al., 2008).

In studying at university, it is crucial to be interested in one's field of study (Mikkonen et al., 2009). Generally, lack of interest in one's own field was a most important predictor of drop outs in a major Finnish University (Mäkinen et al., 2004). Students who can give meaning to their study process are more likely to be engaged and motivated.

Hidi and Renninger (2006) presented the model of how interest develops. For instance, university teachers may think that students are either interested or not. Therefore teachers do not always recognise the possibility of considerably improving the development of students' academic interest. This calls for understanding of how and why interest develops during academic studying. The first phase of the four-phase model presented by Hidi and Renninger (2006) is a triggered situational interest. For instance, an interesting lecture may trigger this kind of interest. If situational interest is sustained, it evolves into the second phase, that is, maintained situational interest. The student may read more about the topic or return to listen to the interesting speaker, for example. Situational interest is always motivating, since it evokes curiosity. The third phase is characterised by an emerging individual interest. It takes place, if the student recognises the relevance of the lecture series from the point of view of a topic she has been trying to understand and applies the new ideas in other contexts. If maintained by active deep learning, emerging individual interest may develop into the fourth phase, namely, a well-developed individual interest. This phase calls for individual interest and allows the individual to sustain long-term learning activities.

We do not assume that all students will acquire a well-developed individual interest during an introductory course, even when the aim is to engage the students. In the present study, however, we measure interest contextually and investigate how reported interest is related to time invested in self-study and further, academic achievement.

\section{Study engagement and the flow experience}

Heikkilä and Lonka (2006) showed that motivational factors are crucial in terms of successful higher education study. Heikkilä, Niemivirta, Nieminen and Lonka (2011) further applied a person-oriented approach in order to study individual profiles, instead of relationships among variables. This approach helped to identify the number of individuals characterised by different cognitive-motivational profiles. The study by Heikkilä et al. (2011) demonstrated that it was useful to combine cognitive and emotional aspects for investigations of students' learning in a person-oriented way. Heikkilä et al. (in press) showed that that cognitive and motivational aspects were not only related to study success, but were also connected with the general well-being of teacher students.

Heikkilä et al. (2011) discussed the possibility that "self-directed students", who had the best academic results and who did not suffer from emotional exhaustion, experienced a positive, fulfilling state of mind, referred to as study engagement. The concept of study engagement is defined as vigour, dedication, and absorption (Schaufeli et al., 2002).

Csikszentmihalyi (1988) proposed that it is important to observe people in those moments in their lives when they reach peaks of involvement that produce intense feelings of enjoyment and creativity, called the optimal experience or flow experience. The universal precondition for flow, according to Csikszentmihalyi (1988) is the reasonably high challenge of the task as well as the feeling that one is capable of facing this very challenging trial. No activity can sustain flow for a long time unless both the challenges and the skills become more complex. If people continue at the same level for a longer period of time, they will simply become bored. Flow therefore constantly increases both the complexity of tasks and encourages individuals to develop. This feature makes it such a dynamic force in intellectual evolution: Flow forces people to stretch themselves, to always take on a challenge, and to constantly improve their abilities. If the challenge is high, and the feeling of competence is high, there is a possibility of experiencing flow. In contrast, if the challenge is high, but the person feels inadequate, this results in anxiety. A low level of challenge combined with a higher sense of competence results in boredom or relaxation. Apathy indicates that both competency and challenge are perceived to be low.

Flow is an interesting concept, since it combines cognitive challenges with emotional states. People often report positive affects, such as engagement and enthusiasm, in relation to flow, whereas more negative affects are reported when there is a mismatch between challenges and competencies (Delle Fave \& Massimini, 2005). Litmanen et al. (2011) showed that inquiry-based learning posed higher challenges and produced more intensive emotional states for the students than lecture-based and teacher-centred instruction, since it forced them to work at the upper limits of their competencies.

The development of expertise calls for not only positive affects, but also tolerating anxiety and uncertainties (Bereiter \& Scardamalia, 1993). LindblomYlänne and Lonka (2000) showed that students in 
a student-activating psychology programme experienced anxiety, but this was interpreted as "a constructive friction" (Vermunt \& Verloop, 1999) in the sense that such experience was related to a challenge in developing self-regulatory skills. Such anxiety may be productive and tolerable, when it is a sign of engagement rather than burnout.

Study engagement is usually measured in terms of general tendencies (Schaufeli et al., 2002), whereas flow appears to be more contextual in nature. Measuring flow experiences, for instance, by using CASS, may help us to understand both cognitive and affective aspects of learning (Litmanen \& Lonka, 2008; Litmanen et al., in press; Muukkonen et al., 2007; 2008). In a mass lecture, collecting contextual data may help to see whether students experience flow, anxiety, apathy, or boredom.

The present study investigates study engagement and flow during a student-activating lecture. In order to understand motivational factors, we need to look at real students in real settings, who are pursuing true goals and living their normal lives. Even though the obvious motivation often appears to derive from grades and examinations, it is important that students find personal meaning in their learning (Lindblom-Ylänne \& Lonka, 2000; Lonka, 1997).

\section{A model of engaging lectures}

We argue that meaningful learning, aiming at conceptual change and understanding is most likely to develop in meaningful social interaction. In Finland, interactive and studentactivating methods have become increasingly popular during the last decades (e.g., Lonka \& Ahola, 1995; Muukkonen, Lakkala, \& Hakkarainen, 2005; Tynjälä, 1999). Such methods have been applied to transform teacher-centred lectures that sometimes involve hundreds of students into reflective inquiries and collaborative experiences (Cantillon, 2010; Jenkins, 1992; Lonka, 1998; Lonka \& Saarinen, 2000).

When trying to reconceptualise lecturing, the main challenge is to understand the process-oriented, $\mathrm{cu}$ mulative and cyclical nature of the learning process of students. In some cases the goal is to enhance the development expertise at a personal level, but often the target is to promote collective knowledge-creation practices. In scientific or professional work, it is essential to work with shared knowledge objects, tools, or systems to be developed (Hakkarainen et al., 2004). In many cases, the students have to deal with extremely complex systems, such as gene technologies, physiological models, or educational practices. The comprehension of such phenomena requires active mental effort. It is essential that lectures stimulate self-study and conceptual change, rather than just transmission of knowledge. The lecturer needs to know the subject matter, understand how people learn and turn their own expertise into something that is comprehensible from the point of view of others. Sometimes this may be done by using rhetorical means, but often it is necessary to use studentactivating methods (Jenkins, 1992; Lonka \& Ahola, 1995; McKeachie, 2006).

The present theoretical model aims to develop an integrative model of engaging instruction. The integrative model depicts learning as a cyclical knowledge advancement process. It involves an iterative process of 1) diagnosing current knowledge and understanding and activating the prevailing process to guide and direct the learning process, 2) going through and supporting various inquiries in which new knowledge and understanding is produced, and 3) assessing learning gains and knowledge produced so as to engage in a deepening learning (Lonka \& Ahola, 1995). The core principles of the present model helps to take undergraduate education closer to the inquiries involved in professional work (Hakkarainen et al., 2004). The model relies on the following principles (modified on the basis of Lonka \& Ahola, 1995; Lonka, 1998):

1) Diagnosing and activating current understanding and knowledge. The learning process always starts by activating a meaningful context in students' minds. The learning process starts with assessing the prevailing knowledge and understanding that form the basis for setting the goals and objectives and specifying the joint targets of investigation. While the objectives are in the context of some university courses provided by curriculum or teachers, engaging lectures involve the participants themselves using their current understanding to guide the development of that understanding. In many cases, this process involves diagnosing the quality and level of students' (mis) conceptions at the beginning of instruction. The same exercises that make diagnosing possible, such as externalising ideas by drawing or writing, assists students to activate their previous knowledge in conjunction with becoming aware of differences between their own conceptions and those of the fellow students or those embedded in textbooks. Innovative pedagogical practices dictate that this process of diagnosing must have an effect on how instruction will proceed. Such new concepts and theories that challenge or conflict with previous beliefs demand special attention. For instance, an engaging lecture would start with short writing or discussion exercises or a pre-test.

2) Fostering the learning process and reflective thinking. It is essential to carry students' strategies 
and knowledge over to discussion and reflection during the learning process. This may be done, for example, by using diaries or learning logs, computer-supported collaborative learning, small group discussions, or mind-mapping. It is important to motivate self-directed learning and personal and collaborative study efforts between lectures. Students should actively take part in small group activities and support each other by discussing, sharing, and building knowledge. Learning new concepts presupposes a dialogue both between the teacher and the students and amongst the students (explaining, debating, questioning). In addition to face-to-face interaction, ICT offers several opportunities to share and build ideas collaboratively. This may be done through newsgroups, email, Learning Management Systems (LMS), such as wikis, or computer-supported collaborative learning environments, which permit the knowledge produced by the participants to be organised, represented and shared efficiently.

3) Assessing change and giving feedback. Students should get constructive feedback from both their peers and from the teacher. This feedback should foster the development of students' thinking and conceptual change and facilitate and guide further inquiries. After the course is over, it is important to clarify what was the basis of the evaluation and how the student might enhance study habits and approaches in order to improve their result and performance in the future. Learning is more effective in situations that simulate real-life. From the point of view of interest, the context in which new ideas are learned, rather than the ideas themselves, has an important influence on learning.

\section{THE CONTEXT OF THE STUDY}

As a part of the Bologna Process in Europe, Finland launched a reform of her higher education system in 2005. The University of Helsinki considers the 3-year bachelor's degree to be an interim degree towards the master's degree. In general, there is no selection process in the transition from the bachelor's level studies to the master's level studies. The kindergarten teacher qualification is an exception to this rule: it only includes the bachelor's degree.

Teacher education is very popular in Finland and only ten percent of those who apply get in to the 5-year Master of Education programme for future elementary school teachers. Even though it is somewhat easier to get into the 3-year kindergarten teacher education programme (Bachelor of Education), it is reasonable to argue that the students who participated in the present study form a highly select group.
The course included 24 hours of student-activating lectures in November, 2009. In addition, students were expected to understand the contents of a comprehensive textbook. Two instructors (the first author and an assistant professor) conducted the lecture sessions and assessment.

The course started with a discussion about "why future teachers need educational psychology". The students were asked to share their ideas in pairs for a few minutes. The pairs were then asked to share the ideas with other pairs (snowballing). In the end, the lecturer (the first author) summarised the ideas on Power Point slides. After this, the lecturer presented her own plan for the content of the course that was compared with the students' ideas and then discussed. Only after this, was the course plan finalised.

During some lectures, the students were asked to write "minute papers" about the topic or a central question for 1-3 minutes (McKeachie, 2006). After this, they were asked to read out loud what they have written to a group of 2 to 4 students. The small group then thought about what they knew about the topic and what more they needed to know. Finally, each group presented their summaries and questions to the teacher. The aim of this exercise was both to diagnose and to activate prior knowledge. The knowledge was not given by the teacher, but instead, actively constructed by the learners.

In addition to lectures, the students were encouraged to discuss what they had learned and what more they would like to learn. What puzzled them about the domain? What was problematic in their own learning? The lecturer then read their sample learning logs. In the beginning of the next session, the comments were discussed and feedback given. Also, the idea was to take the comments into account for future instruction and clarify those points that were unclear or complex.

From time to time, the teachers lectured in a quite traditional way. However, since the students continuously engaged in various activities and gradually learned to share their learning process with others, they were more likely to participate in discussion. The teachers intended not to be too rigid. They did not plan a very tight lecture schedule beforehand. Instead, they reminded themselves to emphasise the core concepts that the students were supposed to understand by the end of the session. Further, it was highlighted that the students should be able to apply psychological knowledge in the school context, since previous research indicates that a six-week course in educational psychology may not produce changes to students' ideas on learning (Lonka, Joram, \& Bryson, 1996).

Assessment that aims to measure change in thinking and understanding is an essential part of an 
engaging lecture. In the present course, the assessment was based on two broad essays that called for an understanding of the contents and applying them in the context of the teacher's future work. The students were told beforehand that they would not be rewarded for recalling minor details, but instead, for understanding the principles and central concepts that were actively processed during the course. The students were also encouraged to integrate what they had learned from the textbook in their answers. A feedback session was organised one week after the examination.

\section{AIMS}

In the present study, the students were asked to report the level of challenge, interest and academic emotions experienced during a student-activating lecture course, and also how they assessed their own competence during the course. The measurements were contextual in nature, and the data were collected five days before the examination.

The first aim was to explore the relationships between academic emotions, the level of challenge experienced in the task, sense of competence, self-study time, and study success on the student-activating lecture course. It was expected that positive emotions would correlate positively with each other and also, with more time spent on self-study. It was assumed that reporting positive emotions would be related to simultaneously reporting high levels of both challenge and competence. In contrast, anxiety would be related to higher levels of challenge than competence.

Since the objective of the course was to engage students during the student-activating lectures, it was assumed that interest and enthusiasm would be reported. Since mainly first-year students were involved and the course content was very demanding, it was anticipated that the level of challenge experienced would generally be high. A strong sense of competence, however, was expected to be related to better preparation (longer self-study time), more positive emotions and better learning outcomes. A weak sense of competence, in contrast, was expected to be related to negative academic emotions.

In order to investigate these matters, the second aim was to examine what kinds of subgroups could be found to classify the participants according to their responses to academic emotions, challenge of the task and experienced competence. It was assumed that those students who reported engagement, flow and positive academic emotions, would study more intensively and do well in the course examination.

\section{METHOD}

\section{Participants}

The participants were 107 first-year elementary- and kindergarten teacher students who attended an introductory course in educational psychology at the University of Helsinki. Overall, $77.3 \%$ of the students who attended the course filled in the questionnaire used in this study. The ages ranged from 19 to 51 years (mean 23.6, SD 5.37). Women (85.0\%) were overrepresented in this study compared to men (15.0 $\%)$, which reflects the gender distribution in teacher education at the University of Helsinki.

\section{Data collection}

The data were collected in December, 2009 from students attending a student-activating lecture course in educational psychology. The participants filled in a questionnaire during the last lecture of the course, five days before the course examination.

The purpose of the study was explained to all participants. It was emphasised that the involvement was voluntary and that the participants could decide not to complete the questionnaire at any time. All participants signed an informed consent form, including consent to gather the course grades. Of the 107 participants, 92 both filled in the questionnaire and attended the course examination. In statistical analyses the largest possible number of participants was included in each analysis.

\section{The materials}

The self-report questionnaire consisted of Likerttype questions to assess academic emotions, motivational factors, problems in studying and procrastination. In this study, we focused on academic emotions, the level of challenge experienced in the task and the students' sense of competence, and each was measured on a situational level. Academic emotions were assessed using a modified PANAS scale (Watson, Clark \& Tellegen, 1988; Tolvanen et al., 2011), consisting of four positive affects (interest, enthusiasm, determination, energy) and four negative affects (irritation, nervousness, anxiety, exhaustion). The questionnaire also addressed single-item measures relating to the challenge of the task ("How challenging is this course?") and self-efficacy ("How competent do you feel in this course?"). All items were answered using a Likert-scale ranging from (1) not at all to (7) very much. In addition, the participants were asked to evaluate how many hours they had spent in self-study by the time they filled in the questionnaire. 
Study success was measured by using the grade obtained from the course from which the data were collected. The course examination was arranged five days after the last lecture and called for understanding and application of knowledge, and learning details by heart was not rewarded. The final grade was given on European Credit Transfer and Accumulation System (ECTS) scale of 1-5 (from poor to excellent).

\section{Statistical analysis}

The statistical analysis began with a descriptive analysis. Bivariate correlations were computed to examine the relations between academic emotions, the challenge of the task, the sense of competence, self-study time and study success. After this a clustering-bycases procedure was used to classify the participants on the basis of their responses to academic emotions, the challenge of the task and the sense of competence. This person-oriented approach revealed what kind of groups of individuals comprised the population.

A hierarchical cluster analysis, selecting the squared Euclidan distance as a similarity measure, was carried out in order to determine the number of clusters. Ward's method was used to form the initial clusters without restricting their number. On the basis of the dendrogram, a three-cluster solution was selected. After deciding the number of clusters, a Quick Cluster Analysis using a K-means algorithm was used to form the final groups. Finally, two ANOVAs were conducted to examine between-group differences across the criterion variables self-study time and study success.

\section{RESULTS}

Table 1 shows means, standard deviations, scales, minimum and maximum scores, and number of cases for each variable. The participants found the course very interesting. They were also quite enthusiastic and determined five days before the course examination. The course was found to be challenging, and the sense of competence they experienced was lower than the level of challenge they experienced.

\section{Correlations}

Our first question concerned the relationship between academic emotions, experienced challenge of the task, sense of competence, self-study time, and study success. In order to explore these relations, bivariate correlations were calculated. Table 2 shows that interest, enthusiasm, determination, and energy all correlated positively with each other, whilst irritation, nervousness, anxiety and exhaustion mutually correlated as well. There were mainly negative correlations between positive and negative affects. The challenge experienced correlated positively with interest, nervousness, and anxiety. The sense of competence had positive correlations with all the positive emotions, but negative correlations with all the negative emotions. Self-study time correlated positively with all the positive emotions and with the sense of competence. Study success was positively related with interest, enthusiasm, sense of competence, and self-study time.

Table 1. MEANS, STANDARD DEVIATIONS, SCALES, MINIMUM/MAXIMUM VALUES PER SCALE, AND THE NUMBER OF CASES

\begin{tabular}{lccccc} 
& Variable & SD & Scale & Mino/Max. & $N$ \\
\hline Interest & 5.25 & 1.20 & $1-7$ & $1 / 7$ & 107 \\
\hline Enthusiasm & 4.54 & 1.27 & $1-7$ & $1 / 7$ & 106 \\
\hline Determination & 4.16 & 1.20 & $1-7$ & $1 / 7$ & 105 \\
\hline Energy & 3.52 & 1.24 & $1-7$ & $1 / 7$ & 106 \\
\hline Irritation & 2.73 & 1.44 & $1-7$ & $1 / 7$ & 105 \\
\hline Nervousness & 3.65 & 1.61 & $1-7$ & $1 / 7$ & 106 \\
\hline Anxiety & 3.70 & 1.82 & $1-7$ & $1 / 7$ & 106 \\
\hline Exhaustion & 3.76 & 1.48 & $1-7$ & $1 / 7$ & 107 \\
\hline Challenge of the task & 5.16 & 1.04 & $1-7$ & $3 / 7$ & 107 \\
\hline Sence of comptence & 3.83 & 1.19 & $1-7$ & $1 / 7$ & 107 \\
\hline Self-study time (h) & 12.19 & 11.08 & & $0 / 60$ & 103 \\
\hline Study success & 3.59 & 0.76 & $1-5$ & $2 / 5$ & 92 \\
\hline
\end{tabular}


Table 2. PEARSON PRODUCT-MOMENT CORRELATIONS BETWEEN ACADEMIC EMOTIONS, CHALLENGE PRESENTED BY THE TASK, SENSE OF COMPETENCE, SELF-STUDY TIME, AND STUDY SUCCESS

\begin{tabular}{|c|c|c|c|c|c|c|c|c|c|c|c|}
\hline & 1 & 2 & 3 & 4 & 5 & 6 & 7 & 8 & 9 & 10 & 11 \\
\hline \multicolumn{12}{|l|}{ Interest } \\
\hline Enthusiasm & $.720^{* *}$ & & & & & & & & & & \\
\hline Determination & $.211^{*}$ & $.445^{* *}$ & & & & & & & & & \\
\hline Energy & $.452^{* *}$ & $.599 * *$ & $.562^{* *}$ & & & & & & & & \\
\hline Irritation & $-.508^{* *}$ & $-.503^{* *}$ & -.133 & $-.415^{* *}$ & & & & & & & \\
\hline Nervousness & -.044 & -.141 & -.103 & -.181 & $.442^{* *}$ & & & & & & \\
\hline Anxiety & -.122 & $-.284^{* *}$ & $-.227^{*}$ & $-.403^{* *}$ & $.479^{* *}$ & $.594^{* *}$ & & & & & \\
\hline Exhaustion & -.151 & $-.329 * *$ & -.186 & $-.376^{* *}$ & $.551^{* *}$ & $.502^{* *}$ & $.698^{* *}$ & & & & \\
\hline Challenge & $.309^{* *}$ & $.198^{*}$ & .025 & .064 & -.050 & $.253^{* *}$ & $.259^{* *}$ & $.240^{*}$ & & & \\
\hline Competence & $.449^{* *}$ & $.541^{* *}$ & $.511^{* *}$ & $.538^{* *}$ & $-.367^{* *}$ & $-.382^{* *}$ & $-.422^{* *}$ & $-.384^{* *}$ & -.116 & & \\
\hline Self-study time & $.347^{* *}$ & $.290^{* *}$ & $.319^{* *}$ & $.255^{* *}$ & .050 & .134 & .074 & .050 & $.209^{*}$ & $.277^{* *}$ & \\
\hline Study success & $.405^{* *}$ & $.257^{* *}$ & .056 & .178 & -.114 & -.137 & -.073 & .138 & .088 & $.304^{* *}$ & $.330 * *$ \\
\hline
\end{tabular}

\section{Group profiles and their relation to self-study time and study success on a student-activating course}

In order to reveal subgroups of students, we used a cluster analysis by cases to classify the participants according to their responses to questions on academic emotions, the challenge of the task, and their sense of competence. The results from ANOVA tests on clustering variables show the extent to which each variable differentiated the groups (Table 3 ).

The groups differed statistically significantly on all clustering variables with effect sizes $\left(\eta_{p}{ }^{2}\right)$ ranging from .15 to .55 (see Table 3). Pairwise comparisons, however, suggested variation in the patterns of differences across the groups. All groups differed significantly from each other in terms of nervousness, anxiety, exhaustion, and sense of competence while pairwise differences were detected on all the other variables. Group $1(n=37)$ had a positive emotional profile with high scores on all the positive emotions, a low score on irritation, and average scores on nervousness, anxiety, and exhaustion. In addition, Group 1 reported both high levels of challenge and strong evaluations of competence. Group $2(n=26)$ represented an "easy going" profile: it had the lowest scores on all the negative emotions and average scores on all the positive emotions. The second group perceived the course as least challenging and scored at an aver- age level on competence. Group $3(n=41)$ had a negative emotional profile: this group scored highly on all the negative emotions except for irritation, averagely on interest, enthusiasm and determination, and low on energy. The third group reported a high level of challenge but weak competence. The three groups were labelled, according to the score means profiles, as (1) engaged (36\%), (2) unstressed (25\%), and (3) anxious students (39\%).

Finally, we performed two ANOVAs to examine whether self-study time and study success were related to the group profiles (Table 4). First, we examined whether there were differences between the groups in self-study time. The main effect was significant for self-study time, $\mathrm{F}(2,97)=4.88, \mathrm{p}=.010, \eta_{\mathrm{p}}{ }^{2}=$ .09. Pairwise comparison with Bonferroni's correction revealed that engaged students had spent more hours in self-study than either unstressed students or anxious students. The latter two groups did not differ from each other in terms of self-study time.

Study success was assessed by means of the course examination. The main effect was significant for course grade, $\mathrm{F}(2,86)=5.35, \mathrm{p}=.006, \eta_{\mathrm{p}}{ }^{2}=.11$. Table 4 shows the pairwise comparisons revealing that engaged students received the highest grades and were more successful in the course than unstressed students, who got the lowest grades. Interestingly, anxious students did not statistically significantly differ from the two other groups, in terms of study success. 
Table 3. MEANS, STANDARD DEVIATIONS, AND ANOVA RESULTS FOR GROUP DIFFERENCES ON ACADEMIC EMOTIONS, CHALLENGE OF THE TASK, AND SENSE OF COMPETENCE

\begin{tabular}{|c|c|c|c|c|c|c|c|c|c|}
\hline \multirow[b]{2}{*}{ Variable } & \multicolumn{2}{|c|}{$\begin{array}{l}\text { Engaged } \\
n=37\end{array}$} & \multicolumn{2}{|c|}{$\begin{array}{c}\text { Unstressed } \\
n=26\end{array}$} & \multicolumn{2}{|c|}{$\begin{array}{c}\text { Anxious } \\
n=41\end{array}$} & \multirow[b]{2}{*}{$F(2,101)$} & \multirow[b]{2}{*}{$p$} & \multirow[b]{2}{*}{$n_{p}^{2}$} \\
\hline & M & SD & M & SD & M & SD & & & \\
\hline Interest* & 6.14 & .59 & $4.73_{\mathrm{a}}$ & .83 & $4.80_{a}$ & 1.38 & 21.04 & $<.0001$ & .29 \\
\hline Enthusiasm & 5.62 & .76 & $4.19_{a}$ & 1.02 & $3.76_{a}$ & 1.09 & 38.35 & $<.0001$ & .43 \\
\hline Determination & 5.00 & .88 & $3.73_{a}$ & 1.00 & $3.66_{a}$ & 1.17 & 19.21 & $<.0001$ & .28 \\
\hline Energy & 4.65 & .89 & $3.23 a$ & .76 & $2.68_{a}$ & .99 & 48.10 & $<.0001$ & .49 \\
\hline Irritation* & $2.11_{a}$ & .94 & $2.08_{a}$ & 1.20 & 3.73 & 1.43 & 22.48 & $<.0001$ & .31 \\
\hline Nervousness & 3.27 & 1.39 & 2.35 & 1.13 & 4.83 & 1.22 & 33.42 & $<.0001$ & .40 \\
\hline Anxiety & 3.03 & 1.40 & 2.15 & 1.08 & 5.34 & 1.17 & 61.46 & $<.0001$ & .55 \\
\hline Exhaustion & 3.41 & .98 & 2.50 & 1.30 & 4.88 & 1.14 & 37.81 & $<.0001$ & .43 \\
\hline Challenge & $5.46_{a}$ & 1.02 & 4.50 & .95 & $5.37 \mathrm{a}$ & .89 & 9.04 & $<.0001$ & .15 \\
\hline Competence & 4.68 & .82 & 3.88 & 1.21 & 3.00 & .87 & 30.47 & $<.0001$ & .38 \\
\hline
\end{tabular}

Note: Means within a row sharing the same subscripts are not significantly different at the $p<.05$ level. Due to unequal variances, Games-Howell correction instead of Bonferroni was applied for variables denoted with an *.

Table 4. MEANS, STANDARD DEVIATIONS AND ANOVA RESULTS ON SELF-STUDY TIME AND STUDY SUCCESS

\begin{tabular}{|c|c|c|c|c|c|c|c|c|c|}
\hline \multirow[b]{2}{*}{ Variable } & \multicolumn{2}{|c|}{$\begin{array}{c}\text { Engaged } \\
n=34\end{array}$} & \multicolumn{2}{|c|}{$\begin{array}{c}\text { Unstressed } \\
\qquad n=26\end{array}$} & \multicolumn{2}{|c|}{$\begin{array}{c}\text { Anxious } \\
n=40\end{array}$} & \multirow[b]{2}{*}{$F(2,97)$} & \multirow[b]{2}{*}{ p } & \multirow[b]{2}{*}{$n_{p}^{2}$} \\
\hline & $M$ & SD & M & $S D$ & $M$ & $S D$ & & & \\
\hline Self-study time & 16.60 & 10.43 & $8.54_{a}$ & 11.97 & $10.44_{a}$ & 10.19 & 4.88 & .010 & .09 \\
\hline Study success & $3.90 \mathrm{a}$ & .75 & $3.27_{b}$ & .63 & $3.47_{\mathrm{ab}}$ & .77 & 5.35 & .006 & .11 \\
\hline
\end{tabular}

Note: Means within a row sharing the same subscripts are not significantly different at the $p<.05$ level.

\section{DISCUSSION}

The results demonstrated that the course engaged the participants who were also very interested and experienced a high level of intellectual challenge five days before the examination. The results further indicated that reported interest, enthusiasm, sense of competence, and self-study time correlated positively with the course grade, whereas expressions of feeling anxious, exhausted, irritated, nervous, determined, energetic, or challenged were not significantly related to the course grade.

Three emotional student profiles were identified: engaged (36\%), unstressed (25\%), and anxious (39\%) student groups. Engaged students spent most hours on self-study and received the best grades. Unstressed students were the least active in self-study and also got the lowest grades. The flow experience was only indirectly measured here, based on the relation between experienced challenge and competence. Engaged students simultaneously reported high levels of challenge and strong competence. These experiences were also related to positive academic emotions. Unstressed students were not very anxious, and they invested the least time in studying. Interest and sense of competence were decisive in successful study in this student-activating lecture course. Anxious students expressed the most negative emotions, and also the lowest sense of competence. These results were in line with previous research on flow experience (Delle Fave \& Massimini, 2005). They may also be interpreted on the basis of research by Schaufeli et al. (2002), who demonstrated that burnout was negatively related to study success, whereas commitment was positively related. Those students who demonstrated a higher sense of competence and persistence did better than others. Schaufeli et al. (2002) could not show a causal 
relation between these experiences and study success. At least we could show a temporal relation: academic emotions and sense of competence five days before the examination were positively related to grades. Engagement, in contrast to disengagement, appeared useful in terms of success.

Developing expertise and constantly working at the upper limits of one's competencies do take their toll, when the students are constantly surpassing themselves (Bereiter \& Scardmalia, 1993). This calls for tolerating a great deal of ambiguity and uncertainty. On the other hand, a feeling of being strongly challenged may also promote flow. The present study indicated flow experience during a student-activating course in terms of the relation between challenge and competence. The fact that some students remained unstressed or anxious calls for further reflection: how can we better support their development? It is worth reminding the reader that these students are future teachers, who should be able to regulate not only their own, but also, their pupils' learning and well-being. Therefore it is important to be able to engage increasing numbers of teacher students in active learning. It is possible that the engaging course for some students remained at the level of situational interest, and they failed to develop a personal interest in an educational psychology course.

It is possible that the results obtained from this student-activating lecture course reflected a constructive friction between the learners and increasing demands of the learning environment (Vermunt \& Verloop, 1999). This means that the need to develop increasingly complex skills in problem-solving and self-regulation may cause anxiety and force the students to develop. Lonka and Ahola (1995) showed that psychology students made slower progress during their studying, when the active ways of learning were first introduced. It took several years before the effects truly started to show. Lindblom-Ylänne and Lonka (2000) later demonstrated that these psychology students experienced a constructive friction and feelings of stress, when they were being introduced to the new forms of student-activating instruction. In the long run, however, such friction appeared useful. This is comforting for those university teachers who have to face the frustrations and anxieties of their students, who may expect delivery of facts instead of interactive learning. Jenkins $(1992,74)$ quoted one of the students on an interactive lecture as saying "I was shocked at first that I had to participate in group discussions rather than the usual sit-at-the-back-ofthe-class-and-fall-asleep syndrome."

We measured situational academic emotions and not general study orientations (Lonka, Olkinuora, \& Mäkinen, 2004). We did, however, obtain quite similar results to those of Heikkilä and Lonka (2006) and Heikkilä et al. (2011; in press) who showed that many Finnish first-year students, including teacher students, suffered from issues of motivation and selfregulation. In order to avoid such extra challenges for our students, there may be a need to develop more instructional scaffolding and procedural facilitation for them (Lonka \& Ahola, 1995). We would also like to make use of new interactive technologies in order to facilitate the process of collaborative knowledge building (Bonk \& Graham, 2006). A project entitled Engaging Learning Environments in Teacher Education is underway at the Faculty of Behavioural Sciences of the University of Helsinki. It will be introduced during the Helsinki World Design Capital 2012 year. The intention is to use the most modern interactive technology that is available. We are also going to experiment with different virtual platforms to make the knowledge building activities more visible and easier to share.

In the current form, our social practices heavily favour face-to-face interaction. It may be that for some students, varying ways of learning would be advisable. The main challenge is to build blended learning environments that support interaction, knowledge construction, and active learning in mass lectures.

Overall, was delightful to see how motivation started to emerge in the first-year students during the course that was reported on here. In future, we would like to explore what kind of community of practice would help our students to overcome the tedious and challenging phases of learning. The aim should be for collaborative inquiry to lead to gradually deepening learning experiences and towards the increasing degrees of agency and self-regulation in social and cultural practices that allow people to test their limits in a relatively safe environment providing the necessary social support and emotional engagement.

\section{Conclusions}

All cultures share a human tendency to pursue goals and show a pattern of growing complexity in their activities. Flow is not typically fun, amusement or ecstasy, but rather, part of normal daily experience, characterised by concentration and engagement. We wanted to explore how this phenomenon emerges in the context of an engaging lecture.

This study showed how contextual academic emotions play an important role in successful studying. We claim that boredom is the worst poison for any intelligent creature, and especially for young and active people. It appeared that being either slightly anxious or engaged was better than remaining unstressed or even care-less. Personal interest and enthusiasm were especially important in terms of study success on a student-activating lecture course. 
As university teachers, we should be able to provide reasonable challenges for our students (in relation to their skill level) and support their sense of competence. In that way, we can promote flow in our students and motivate them to learn. Flow can be defined as doing something that is worth doing for its own sake - it is the pure joy of working. However, it may be impossible to reach this kind of motivational state without experiencing some anxiety as well (Litmanen et al., in press). A central challenge will be how to retain the balance between flow and anxiety in order to help our teacher students to develop. This is a crucial question in order to make them un- derstand that as future teachers, they need to demonstrate the readiness to facilitate such processes in their own classrooms.

\section{ACKNOWLEDGEMENTS}

This research was funded by The Finnish Funding Agency for Technology and Innovation (TEKES) project RYM Indoor Environment (462054). We are grateful to Dr. Patricia Comley and Mr. Andrew Mulley for helping us with the language revision.

\section{REFERENCES}

Ainley, M., Corrigan, M., \& Richardson, N. (2005). Students, tasks and emotions: Identifying the contribution of emotions to students' reading of popular culture and popular science texts. Learning and Instruction, 15(5), 433-447.

Bereiter, C. (2002). Education and mind in the knowledge age. Mahwah, NJ: Lawrence Erlbaum Associates.

Bereiter, C., \& Scardamalia, M. (1993). Surpassing ourselves. An inquiry into the nature and implications of expertise. Chicago, IL: Open Court.

Bonk, C.J., \& Graham, C.R. (2006). The handbook of blended learning. Global perspectives, local designs. San Francisco, CA: John Wiley \& Sons, Inc.

Cantillon, P. (2010). Teaching large groups. In P. Cantillon \& D. Wood (Eds.), ABC of learning and teaching in medicine. Malaysia: Blackwell Publishing Ltd.

Csikszentmihalyi, M. (1988). The flow experience and human psychology. In M. Csikszentmihalyi \& I.S. Csikszentmihalyi (Eds.), Optimal experience. Psychological studies of flow in consciousness. Cambridge, MA: Cambridge University Press.

Dahlin, M., Joneborg, N., \& Runeson, B. (2005). Stress and depression among medical students: a cross-sectional study. Medical Education, 39(6), 594-604.

Delle Fave, A., \& Massimini, F. (2005). The investigation of optimal experience and apathy: Developmental and psychosocial implications. European Psychologist, 10(4), 264-274.

Gibbs, G., \& Jenkins, A. (1992). Improving teaching and learning in large classes. In G. Gibbs \& A. Jenkins (Eds.), Teaching large classes in higher education. How to maintain quality with reduced resources. London, UK: Kogan Page Limited.

Hakkarainen, K., Palonen, T., Paavola, S., \& Lehtinen, E. (2004). Communities of networked expertise: Professional and educational perspectives. Amsterdam: Pergamon.

Heikkilä, A., \& Lonka, K. (2006). Studying in higher education: students' approaches to learning, self-regulation, and cognitive strategies. Studies in Higher Education, 31(1), 99-117.

Heikkilä,. A., Lonka, K., Nieminen, J., \& Niemivirta, M., (in press). Relations between teacher students' approaches to learning, cognitive and attributional strategies, well-being, and study success. Higher Education.

Heikkilä, A., Niemivirta, M., Nieminen J., \& Lonka, K. (2011). Interrelations among university students' approaches to learning, regulation of learning, and cognitive and attributional strategies: a person oriented approach. Higher Education, 61(5), 513-529.

Hidi, S., \& Renninger, K.A. (2006). The four-phase model of interest development. Educational Psychologist, 41(2), 111-127.

Jenkins, A. (1992). Active learning in structured lectures. In G. Gibbs \& A. Jenkins (Eds.), Teaching large classes in higher education. How to maintain quality with reduced resources. London, UK: Kogan Page Limited.

Lindblom-Ylänne, S., \& Lonka, K. (2000). Dissonant study orchestrations of high achieving university students. European Journal of Psychology of Education, 15(1), 19-32.

Litmanen, T., \& Lonka, K. (2008). Contextual motivation in inquiry-based learning. A paper presented at EARLI (European Association for Research on Learning and Instruction) JURE-Conference, Leuven, Belgium, July 8-11, 2008.

Litmanen, T., Lonka, K., Inkinen, M., Lipponen, L., \& Hakkarainen, K. (In press). Capturing teacher students' emotional experiences in context: Does inquiry-based learning make a difference? Instructional Science.

Lonka, K. (1997). Explorations of constructive processes in student learning. A doctoral dissertation. Helsinki: University Press.

Lonka, K. (1998). The 21st century student - An active learner? An invited theme session keynote lecture in Proceedings of

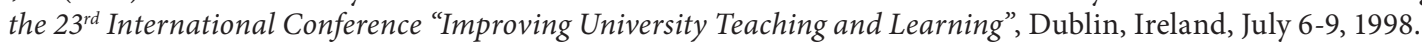

Lonka, K., \& Ahola, K. (1995). Activating instruction: How to foster study and thinking skills in higher education. European Journal of Psychology of Education, 10(4), 351-368. 
Lonka, K., Joram, E., \& Bryson, M. (1996). Conceptions of learning and knowledge: Does training make a difference? Contemporary Educational Psychology, 21(3), 240-260.

Lonka, K., Olkinuora, E., \& Mäkinen, J. (2004). Aspects and prospects of measuring studying and learning in higher education. Educational Psychology Review, 16(4), 301-325.

Lonka, K., \& Saarinen, E. (2000). Think fearlessly: How to activate a group of 700 students? A workshop in Innovations in Higher Education 2000 Conference, Helsinki, Finland, August 30-Sept 2, 2000.

Lonka, K., Sharafi, P., Karlgren, K., Masiello I., Nieminen, J., Birgegård, G., \& Josephson, A. (2008). MED NORD - A tool for measuring medical students' well-being and study orientations. Medical Teacher, 30(1), 72-79.

McKeachie, W.J. (2006). McKeachie's teaching tips: strategies, research, and theory for college and university teachers. Boston, MA: Houghton Mifflin.

Mikkonen J., Heikkilä, A., Ruohoniemi, M., \& Lindblom-Ylänne S. (2009). “I study because I’m interested”: University students' explanations for their disciplinary choices. Scandinavian Journal of Educational Research, 53(3), 229-244.

Muukkonen, H., Hakkarainen, K., Inkinen, M., Lonka, K., \& Salmela-Aro, K. (2008). CASS-methods and tools for investigating higher education knowledge practices. Proceedings of the eighth International Conference for the Learning Sciences, Utrecht University, Utrecht, Netherlands, June 23-28, 2008.

Muukkonen, H., Hakkarainen, K., Jalonen, S., Kosonen, K., Heikkilä, A., Lonka, K., Inkinen, M., Salmela-Aro, K., Linnanen, J., \& Salo, K. (2007). Process- and context-sensitive research on academic knowledge practices: Developing CASS-tools and methods. Proceedings of the Computer Supported Collaborative Learning Conference, Rutgers University, New Jersey, USA, July 16-21, 2007.

Muukkonen, H., Lakkala, M., \& Hakkarainen, K. (2005). Technology-mediation and tutoring: How do they shape progressive inquiry discourse? Journal of the Learning Sciences, 14(4), 527-565.

Mäkinen, J., Olkinuora, E., \& Lonka, K. (2004). Students at risk: Students' general study orientations and abandoning/ prolonging the course of studies. Higher Education, 48(2), 173-188.

Op 't Eynde, P., \& Turner, J. E. (2006). Focusing on the complexity of emotion issues in academic learning: A dynamical component system approach. Educational Psychology Review, 18(4), 361-376.

Pekrun, R. (2005). Progress and open problems in educational emotion research. Learning and Instruction, 15(5), 497-506.

Pekrun, R., Goetz, T., Titz, W., \& Perry, R. (2002). Academic emotions in students' self-regulated learning and achievement: A program of qualitative and quantitative research. Educational psychologist, 37(2), 91-105.

Salmela-Aro, K., \& Schoon, I. (2010, Ed). Youth development in Europe: Transitions and identities. European Psychologist, Special issue editors Vol. 14(4), 372-375.

Scardamalia, M., \& Bereiter, C. (2003). Knowledge building environments: Extending the limits of the possible in education and knowledge work. In A. DiStefano, K.E. Rudestam, \& R. Silverman (Eds.), Encyclopedia of distributed learning. Thousand Oaks, CA: Sage Publications.

Schaufeli, W.B., Martínez, I.M., Pinto, A.M., Salanova, M., \& Bakker, A.B. (2002).

Burnout and engagement in university students: A cross-national study. Journal of Cross-cultural Psychology, 33(5), 464-481.

Tolvanen, A., Kiuru, N., Leskinen, E., Hakkarainen, K., Lonka, K., Inkinen, M., \& Salmela-Aro, K. (2011). A new approach for estimating a nonlinear growth component in multilevel modelling. International Journal of Behavioral Development, 35(4), 370-379.

Trigwell, K., \& Prosser, M. (1996). Congruence between intention and strategy in university science teachers' approaches to teaching. Higher Education, 32(1), 77-87.

Tsai, Y.-M., Kunter, M., Ludtke, O., Trautwein, U., \& Ryan, R.M. (2008). What makes lessons interesting? The role of situational and individual factors in three school subjects. Journal of Educational Psychology, 100(2), 460-472.

Tynjälä, P. (1999). Towards expert knowledge? A comparison between a constructivist and a traditional learning environment in the university. International Journal of Educational Research, 31(5), 357-442.

Vermunt, J.D.H.M., \& Verloop, N. (1999). Congruence and friction between learning and teaching. Learning and Instruction, 9(3), 257-280

Ward, A., \& Jenkins, A. (1992). The problems of learning and teaching in large classes. In G. Gibbs \& A. Jenkins (Eds.), Teaching large classes in higher education. How to maintain quality with reduced resources. London, UK: Kogan Page Limited.

Watson, D., Clark, L., \& Tellegen, A. (1988). Development and validation of brief measures of positive and negative affect: The PANAS scales. Journal of Personality and Social Psychology, 54(6), 1063-1070.

\footnotetext{
* The publishing of this paper was supported by European Social Fund.
} 